\title{
CHEST INJURIES AND COMPLICATIONS IN THE EARLY STAGES OF SPINAL CORD INJURY
}

\author{
By J. R. Silver, M.B., B.S., M.R.C.P.Ed. \\ Liverpool Regional Paraplegia Centre
}

Associated injuries are usually regarded as those injuries acquired at the same time as the injury to the spinal cord. They may be of such magnitude and severity that their treatment takes precedence in the first instance over the management of the spinal injury, for example, a patient with a ruptured spleen will require urgent surgery and resuscitation to save his life. Unfortunately, particularly when there has been a severe head injury, the spinal injury itself may be overlooked to the detriment of the patient. Conversely, when the associated injuries are less flamboyant, they too may be overlooked or neglected to the detriment of the total rehabilitation of the patient. A history of pre-existing illness or drug therapy may not be obtainable or elicited in the stress of dealing with the spinal trauma, only for the illness to manifest itself in an acute form subsequently. Gastrointestinal bleeding may arise either from acute mucosal erosions or from the exacerbation of a pre-existing peptic ulcer. Some of the factors that should be considered in the classification of these injuries are set out in Table I.

Therapeutically prescribed drugs, such as anticoagulants, insulin or steroids are unlikely to be overlooked since their dangers are well recognised, and the patients usually carry a card to warn doctors who may have to treat them as an emergency that they are under treatment. However, this does not apply to selfmedication, in the form of alcohol, cigarettes and, more recently, pep pills. Patients are either unable or loath to admit to a history of heavy alcohol consumption, particularly when it may have been the cause of the accident. A history of heavy smoking, particularly now it is associated with feelings of guilt, may also be difficult to elicit and is of particular importance in the management of chest injuries in paraplegic patients. Pethidine and morphia addiction produced by the attending doctors in the early stages of spinal injury is less prevalent with the better understanding of the treatment of spinal injuries and the early transfer of these cases to specialised centres. However, these drugs too can give rise to difficulties and severe withdrawal reactions. Of increasing importance in adolescence, is the taking of pep pills or other stimulants, these having to a large degree replaced alcohol consumption in this age group. A further group of associated injuries are iatrogenic and produced by a lack of understanding of the basic pathophysiology of spinal cord transection. The complications of urinary infection and pressure sores have been extensively discussed in the past, but the development of chest complications has received little attention. Cameron et al. (I955), Talbot et al. (1957), Wingo (1957), Hemingway et al. (I958), Grossiord et al. (1963), Silver (1963), Bergofsky (1964), Guttmann and Silver (1965) Maglio et al. (1966), have discussed the physiological implications of spinal cord injury, but the only papers on the clinical management of these patients' chest complications have been by Cheshire (1964), Cheshire and Foster (1964), and Cheshire and Coats (1966). These chest complications are largely related to the impairment of the normal mechanisms of breathing in patients with high lesions 
of the cord which impair their ability to cough, since the abdominal and intercostal muscles are paralysed, but they may be aggravated by associated head injuries and damage to the thoracic cage. Unfortunately, they may also be exacerbated by the poor initial management of the patient. In order to assess the relative

\section{TABLE I}

Classification of Associated Injuries of the Spinal Cord

$\begin{array}{ll}\text { I. Pre-existing Illness } & \text { Asthma } \\ & \text { Chronic bronchitis } \\ & \text { Renal disease } \\ & \text { Peptic ulceration } \\ & \text { Old age } \\ & \text { Anticoagulants } \\ \text { Therapeutic Drugs } & \text { Insulin } \\ & \text { Steroids } \\ & \text { Morphia } \\ & \text { Pethidine } \\ & \text { Alcohol } \\ \text { Self-medication } & \text { Smoking } \\ & \text { Pep pills }\end{array}$

2. Overt INJURY . . Head injury particularly associated with cervical fractures

Chest injury particularly associated with thoracic fractures

Pelvic injury particularly associated with lumbar fractures

Extremity fractures-all groups

3. Occult . . . . Skull fractures

Sternum and ribs fractures

Deep vein thrombosis

$\longrightarrow$ pulmonary embolism

4. IATROGENiC . . . Hypostatic pneumonia

Pressure sores

Urinary infection

contribution that these various factors play in the production of chest complications, an analysis was made of the associated injuries with particular reference to the chest complications in all the patients admitted to the Liverpool Regional Paraplegic Centre from 5 July 1965 to 5 July 1967.

Clinical Material. All the new traumatic cases admitted to the Liverpool Regional Paraplegic Centre between 5 July 1965 and 5 July I967 were studied. They were all treated personally by the author (see Table II). The number of acute admissions during the two years would appear to be comparable with other centres of similar size serving comparable populations (Gregg, 1967). The large number of cervical patients (29, comprising more than half the total admissions) is probably representative of the better understanding of the problems 


\section{TABLE II}

Analysis of 50 Traumatic Cases

Sex: $\quad 40$ males, ro females

Age: $\quad$ 12-77 years

Deaths: 8

\begin{tabular}{|c|c|}
\hline Levels: & Cervical \\
\hline & Thoracic \\
\hline
\end{tabular}

Cause: Road traffic accidents . . . 25

Falls (2 suicides, I hysteria) . I9

Blows on the back . . . 4

Dive . . . . . I

Pathological (multiple myeloma . I

FIG. I

Analysis of the time of admission of the 50 traumatic cases.
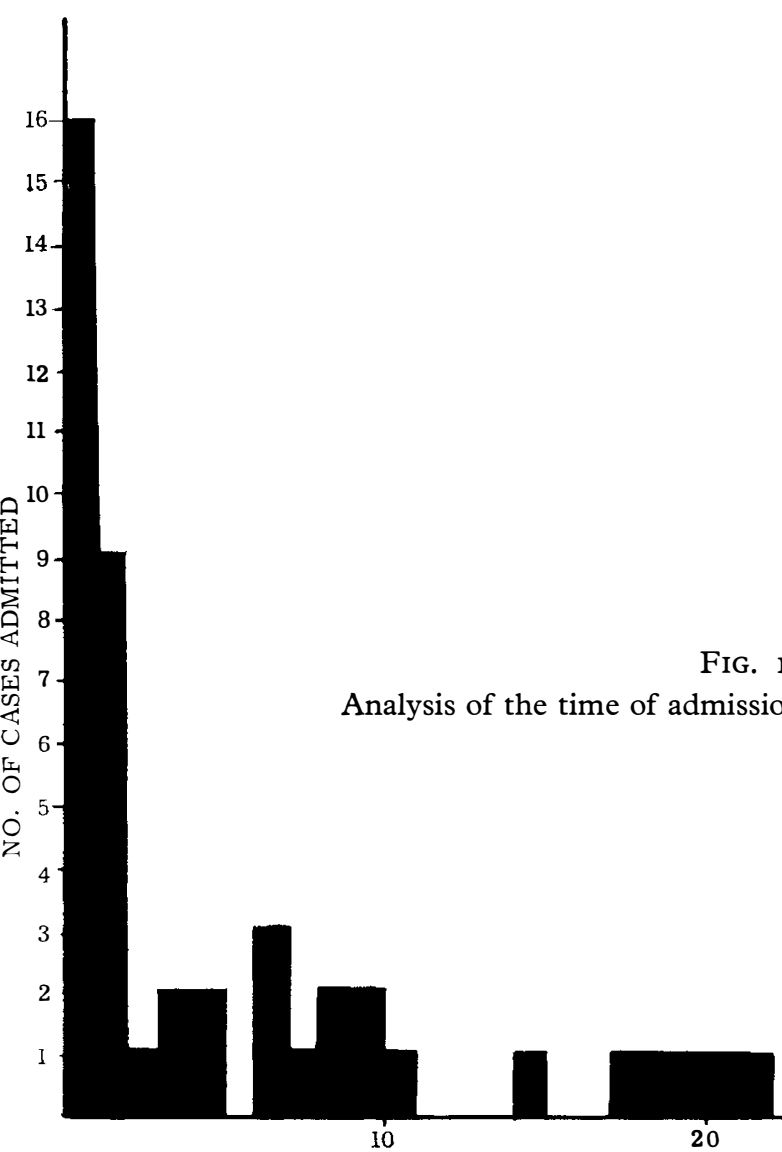
of the treatment of paraplegia by orthopaedic and general surgeons who transfer these cases rapidly to the Spinal Centres. This is shown in figure I. It is encouraging that 25 of the patients were admitted within 48 hours of injury and only five patients were admitted more than one month after injury. Four of these five patients admitted late had pressure sores, two patients, both of whom had sores, admitted at 22 and 58 days were addicted to Pethidine. This lead to great behaviour difficulties during the withdrawal phase, but it is gratifying that they both made a superb rehabilitation and both drive their own cars to attend full University and Technical Courses.

The Influence of Associated Injuries and the Muscular Paralysis upon the Production of Chest Complications. The associated injuries

\section{TABLE III}

Analysis of the Type of Associated Injury

I7 Nil

33 Head Injuries, Chest Injuries or Extremity Fractures
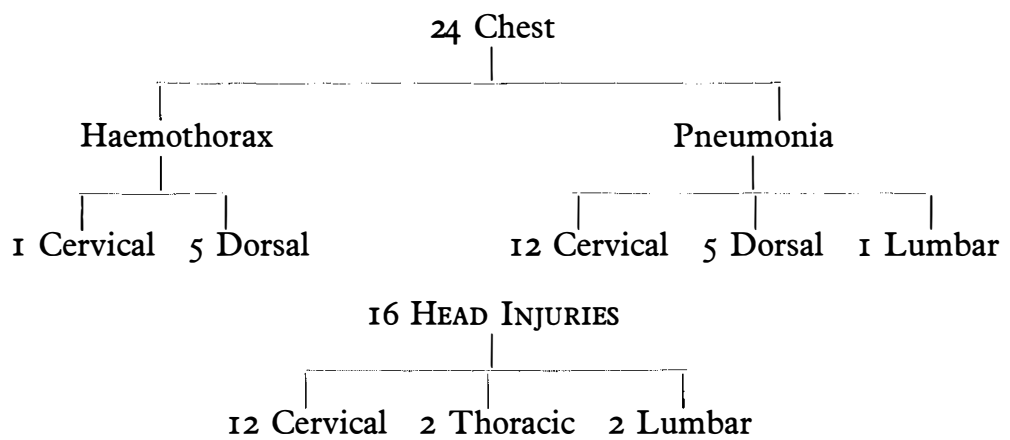

$\begin{array}{lll}7 \text { Severe: } & 4 \text { Cervical } & 9 \text { Combined Head and Chest Injuries } \\ & 3 \text { Thoracic } & \text { Only } 2 \text { Fatal }\end{array}$

9 Extremities Fractures

\begin{tabular}{llc}
$\quad$ Cervical & \multicolumn{1}{c}{ Dorsal } & \multicolumn{1}{c}{ Lumbar } \\
Radius & Colles & Femur + tibia fractures \\
Humerus & Tibia & \\
Tibia & Metatarsal & \\
Patella & Radius &
\end{tabular}

found in the 50 patients are set out in Table III. Numerically, the chest complications and particularly the occurrence of an aspiration pneumonia was the most significant finding. The symptoms of pneumonia were often minimal, the patient and staff being pre-occupied with the pain at the fracture site and the general management of the paralysed parts. However, a history of cough, chest discomfort, a shoulder tip, pain on breathing, or a choking sensation could sometimes be elicited when specifically requested. The signs were often minimal consisting 
of tachycardia, rapid sỉallow breathing. Occasionally the patients were cyanosed but this was unusual. The signs in the chest were a few scattered moist sounds. The interpretation of impairment of movement and percussion note and air entry at the bases was extremely difficult in the presence of paralysis of the intercostal and abdominal muscles with the frequently associated paralytic ileus pushing up the diaphragm. In most cases, it was difficult to obtain sputum and when this was obtained it was mucoid and the organisms were non-specific. For this reason, almost exclusive reliance was placed upon chest X-rays of necessity taken with a portable machine. Repeated X-rays were easily obtained and it should be stressed that it was regarded as essential that lateral projections were obtained. This is of particular importance in tetraplegic patients who are confined to bed, because owing to the extensive muscular paralysis and the inability of the patients to sit up, the diaphragm assumes a higher position when the patient is recumbent so that a greater portion of the lung will be hidden behind the dome of the diaphragm and will not be visible on the anterior-posterior projection. The X-ray of the chest is always taken on admission and is regarded as the most important X-ray to be taken of the patient and is repeated on alternate days in the management of the chest complications. The most important finding was that many of the patients who made no complaint of any chest symptoms had $\mathrm{X}$-ray evidence of pneumonia. This was in all cases but two in the posterior basal segment of the lower lobe. In one case there was an associated middle lobe pneumonia, and in another case, a boy injured diving, it was in the left upper lobe of the lung. The association of pneumonia with the level of the lesion is very striking, in that 17 of the 18 patients in whom pneumonia was found were those with paralysed abdominal muscles, demonstrating the importance of these muscles in coughing and forced expiration. Twelve out of 29 patients with injuries to the cervical region, 5 out of 15 patients with injuries to the thoracic region, but only I out of 6 patients with injuries to the lumbar region had pneumonia. It is not to be supposed that all these patients had pneumonia before they were injured, since they were healthy adults with no previous history of coughs or colds or upper respiratory tract infections and in some of the cases they had clear initial X-rays on admission either at the receiving Hospital or at the Liverpool Regional Paraplegic Centre.

Mr. P. M., aged 49, was demolishing a surface air-raid shelter on I.7.67, some 22 years after the war had ended, when the roof slipped and struck him at the right occipital region. He was knocked momentarily unconscious and sustained a fractured cervical spine at the 6th cervical vertebra with an incomplete tetraplegia below that level. An initial chest X-ray at the receiving hospital was quite normal. Skull traction was instituted but he was not turned and received no breathing exercises or postural drainage. He lay flat on his back without being turned. He developed a paralytic ileus and commenced vomiting. He inhaled a mixture of nasal secretions and vomit. On admission to the Liverpool Regional Paraplegic Centre on 3.7.67, some three days after his injury, an X-ray of his chest revealed inflammatory changes at the basal segment of his right lung. X-ray of his abdomen showed fluid levels compatible with a paralytic ileus. $\mathrm{He}$ commenced postural drainage, breathing exercises, inhalations (Orciprenaline Sulphate), systemic antibiotics and all food by mouth was discontinued. His stomach was aspirated two-hourly by means of a Ryles tube and he received intravenous fluids. Profuse sputum was obtained from the right side of the chest over the next few days which grew no organisms on culture. Subsequent X-rays of his chest (6.7.67) showed a considerable improvement and within a short while he showed evidence of recovery 
of sensation and power in his lower limbs. Finally (2.8.67) X-ray showed a completely clear chest. He is now up in a chair, beginning to feed himself and wheel his chair to the Occupational Therapy and. Physiotherapy Department.

This case illustrates that secretions drain to the most dependant portion of the lung. These cannot be expelled in the presence of extensive respiratory muscle paralysis, this being further aggravated by the paralytic ileus which distends the abdomen and diminishes the excursion of the diaphragm. Further damage being caused by the aspiration of stomach contents and mucus from his nose. In this case there were many factors leading to the production of a pneumonia. However, even one factor alone can lead to the production of a pneumonia even in the later stages when there is a paralysis of the abdominal muscles, showing that the tetraplegic patients are always at risk, as illustrated by the following case:

Miss D. T., aged 26, sustained a severe head injury, multiple fractured ribs, a fractured scapula, a fractured clavicle and an incomplete tetraplegia as a result of an injury to her cervical spine in a car accident on 8.10.66. Tracheostomy was performed and she was treated with positive pressure respiration. She was transferred with the tracheostomy still in situ some 28 days after injury to the Liverpool Regional Paraplegic Centre. Chest X-ray taken on 7.1 I.66 was normal. Her tracheostomy was discontinued and she began to sit up. However, she was heavily addicted to cigarette smoking and she had a productive mucoid cough and despite repeated attempts to deprive her of her cigarettes she still persisted in smoking. During the Christmas festivities she developed a cold and became suddenly breathless and acutely ill (28. I2.66). X-ray confirmed a total collapse of her right lung which could not be re-expanded, despite vigorous postural drainage (fig. 2). She was taken to the Theatre where a bronchoscopic aspiration was performed to her immediate relief. Further X-ray on 9.I.67 showed complete reexpansion (fig. 3).

Patients with paralysed abdominal muscles and intercostal muscles, that is the tetraplegic and high thoracic patients, are always at risk of developing bronchopneumonia when they develop an upper respiratory infection, particularly when they are smokers, since the nicotine or cigarette smoke has the dual harmful effect of damaging the cilia and producing hypersecretion of mucus. Consequently, any tetraplegic who develops a cold is immediately treated by postural drainage and placed on systemic antibiotics and Orciprenaline inhalations two-hourly, in much the same way as a severe chronic bronchitic is treated.

Finally, to demonstrate that even when a patient has intact abdominal muscles with powerful expiration, if the fundamental principles are neglected, pneumonia can be produced.

M. W., aged 42, sustained a fracture of LI and a fracture of his left femur and tibia as a result of a coal tip falling on his back on I5.I I.65. On admission to Southport, two days after injury, he had some inflammatory changes at the right base of his lung and an effusion. In order to clear this and to prevent him getting pain from the movement of his fractured left lower limb, the fundamental principles of treatment were neglected and he was nursed on his left side and back. By the fifth day after admission he was complaining of pain in the left side of his chest. X-ray revealed that while the right side was now clear he had developed a left-sided pneumonia. When he commenced a regime of lying on both sides and his back, the chest rapidly cleared up. 


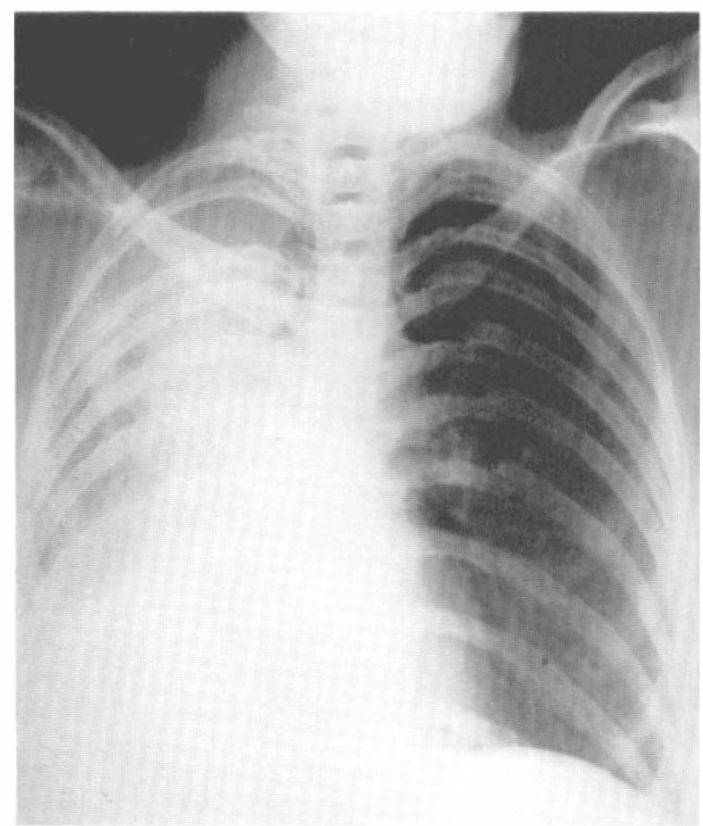

FIG. 2

Chest X-ray, D. T., 28.I2.66. Total collapse of the right lung.

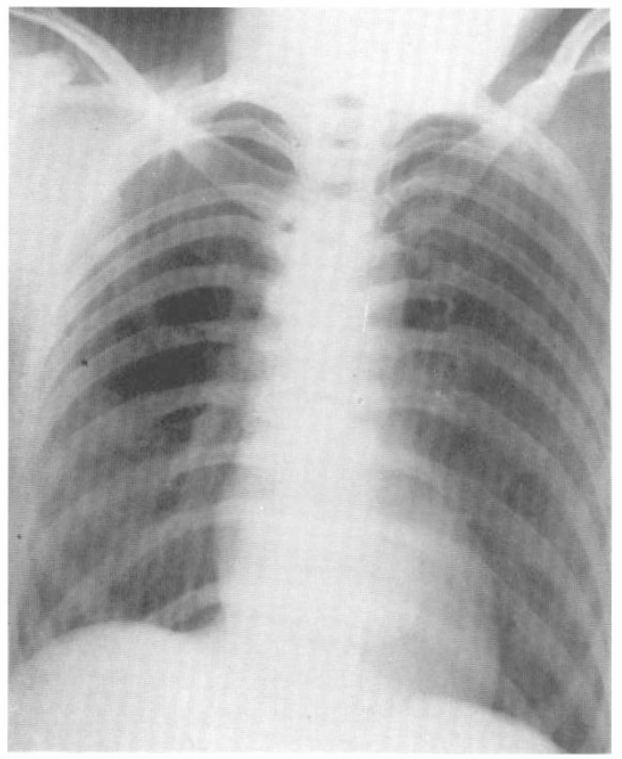

FIG. 3

Chest X-ray, D. T., 9.I.67. Re-examination of right lung following treatment. 
Influence of Head Injuries upon Chest Complications. Owing to the mechanism of production of many of the fractures of the cervical spine, that is by a blow on the head, severe head injuries are frequently present and often associated with damage to the rib cage. Of the seven patients with severe head injuries, two had fractured ribs with haemothoraces, four had pneumonias and only one patient escaped with no chest complications. A head injury will facilitate the development of a pneumonia by two mechanisms. On the one hand the depression of the respiratory excursion means that distal segments of the lung are not ventilated so that they collapse. On the other hand, the concomitant abolition of the cough and gag reflex permits stomach contents and nasal secretions to drain to the lowermost portion of the lung. Patients with head injuries are naturally unable to co-operate with the nursing and physiotherapy staff.

Mr. M. W., aged 2I, was struck on his head and neck by an 80-lb. case of New Zealand butter while working on a ship on I2.I0.66. He was knocked unconscious, he sustained several broken teeth, a fracture of his 5 th cervical vertebra, a fracture of his sternum and a complete tetraplegia initially below $\mathrm{C}_{5}$. He was transferred to the Liverpool Regional Paraplegic Centre one day after injury. For many weeks his level of consciousness fluctuated between deep coma and severe confusion with signs of cerebral irritation. His initial chest X-ray was normal. He followed the usual regime of treatment in the Centre with postural drainage, chest percussion and passively forced expiration. This naturally presented some difficulty since the level of consciousness rendered co-operation impossible. Some two weeks after injury he was observed to have some collapse of his right base with an elevated right diaphragm. These changes disappeared when special efforts were directed to draining this part of his lung. After a long protracted course of rehabilitation he is now sitting up in a chair, feeding himself and shows faint signs of sensory recovery in his left foot, some I I months after injury.

The Influence of Fractured Ribs upon Chest Complications. Another major cause of chest injuries is fractures in the mid-thoracic region. Patients who sustain a mid-thoracic fracture are particularly liable to chest complications. By virtue of the narrowness of the thoracic spinal canal and its rigidity not only are these patients more liable to complete cord lesions thus losing nearly as much expiratory muscle as a low cervical lesion, but the thoracic spinal column is an intra-thoracic structure so that bleeding and haematomas around the fracture site may press upon the lungs, but of far greater importance is the fact that the ribs are attached anteriorly to the sternum and posteriorly to the spinal column, with a consequence that if an injury is of sufficient severity to cause a disruption of the spinal column, producing paraplegia, it is just as likely to fracture the ribs and sternum giving rise to haemothorax. Study of Table III bears out this contention since of the six patients with haemothoraces five of them had dorsal injuries, compared with only one cervical. The mechanism of injury is also of interest since it may result from a crushing blow when the driver of a car crashes into the steering wheel. Four of the six patients with fractured ribs and haemothorax were road traffic accidents; one was the result of a collapse of a trench upon the patient and the other a fall; two other patients of the series of $50 \mathrm{had}$ fractured ribs but no haemothoraces-both were as a result of road traffic accidents.

It should be appreciated that the fractures of the ribs splint the lungs due to the pain. If more severe, the ribs may pierce the pleura and lead to a pneumothorax. The heart, too, may be damaged directly by the fractured ribs or sternum 
at the time of injury. When there are no associated injuries, apart from the haemothorax and the fractured spine, these cases gave rise to little difficulty. Five of the six cases were treated simply by aspiration of the haemothorax on one or two occasions. There was no residual damage to the lungs which was confirmed by subsequent chest X-rays. In one patient there was an associated tension pneumothorax which had to be treated by an underwater-seal drain.

Mr. A. S., aged 2I, sustained a severe head injury and a fracture of his $4^{\text {th }}$ thoracic vertebra in a car crash on 6.5.67. There were no fractured ribs visible on the X-ray but the whole of the left side of his chest was opaque, suggestive of a haemothorax. He was transfused with two pints of blood at the receiving Hospital and was transferred to the Liverpool Regional Paraplegic Centre two days after injury. His general condition was extremely poor. He was very confused from his head injury. He showed signs of

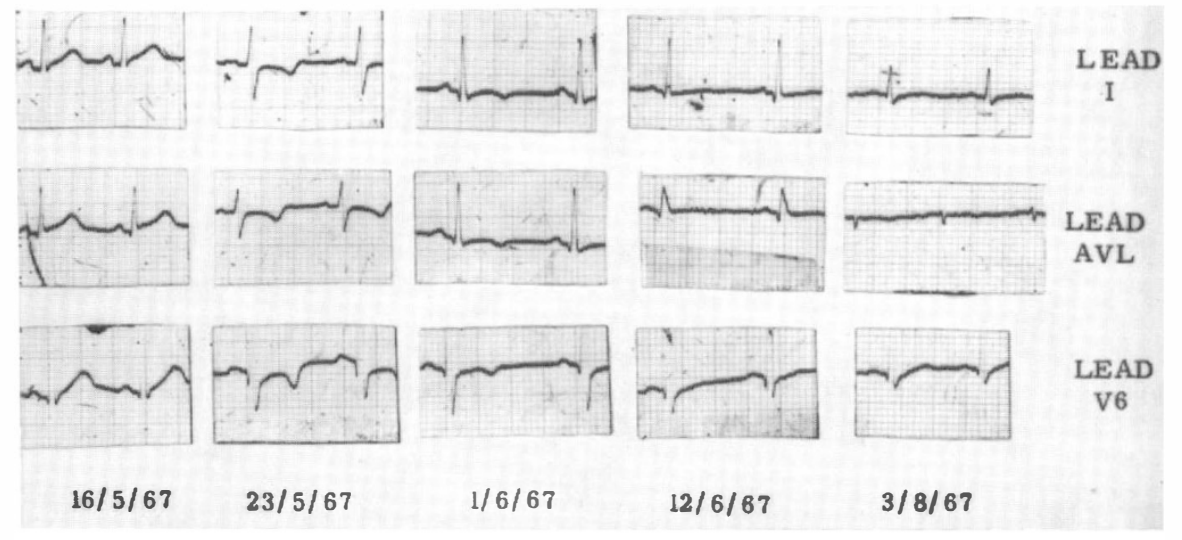

FIG. 4

Serial electrocardiograms on A. S. Note the deterioration between 16.5.67 and 23.5.67 although his clinical condition was improving

cerebral irritation and had a total paraplegia below $\mathrm{T}_{5}$. Four days after injury his condition deteriorated further, he was found to have a tension pneumothorax which was drained by an underwater-seal drain, since the whole of the left lung was collapsed in addition. His condition gradually improved from this but some seven days after injury he developed a friction rub over his heart and this remained until some 26 days after injury he complained of a little chest pain of an indefinite nature. The E.C.G. was strongly suggestive of cardiac damage (fig. 4). In this case the steady improvement in his condition despite the deteriorating electrocardiogram with a pericarditis would seem to point to a direct damage to his heart at the time of his accident, although its appearance some seven days after the injury is of great interest and may be confused with a pulmonary embolus.

In the early stages, the patient may have a coincidental massive pulmonary embolus producing electrocardiographic and cardiac changes that can resemble an acute pericarditis or an acute cardiac tamponade. Three patients in this series had overt pulmonary emboli, one of these with multiple injuries proved fatal.

Mr. H., aged 32, was a passenger in a van which skidded on 28.7.66. He sustained a fracture of $\mathrm{T}_{7}$ with a complete paraplegia below that level. He was admitted the 
same day to the Liverpool Paraplegic Centre. Initially he had patchy collapse of his right lung. He seemed to be making a fairly satisfactory recovery until ig days after injury when he complained of severe headache, and he collapsed and became pale and sweaty. Examination showed that his apex beat was impalpable, his liver was enlarged one hand's breadth below the costal margin, his neck veins were engorged and neither were pulsating. His heart beat was almost inaudible. There was a pleuro-pericardial friction rub. His legs were swollen. The electrocardiogram showed marked T-wave inversion with right ventricular strain. These findings were suggestive of a pericardial tamponade. A Chest Surgeon confirmed the findings and attempted to aspirate the effusion. This was unsuccessful although the patient improved. Consequently, the diagnosis was revised to that of a massive pulmonary embolus. This was subsequently confirmed by the progressive improvement in the electrocardiogram which reverted to normal, the enzyme studies, the initially raised bilirubin $\mathrm{I} \cdot 8$ falling to normal, and rapid decrease in the swollen legs following institution of anticoagulant therapy. This case illustrates the difficulties of diagnosing a pulmonary embolus in the presence of chest injuries and mid-thoracic fracture.

Occult Injuries. Occult injuries may be suspected from the preceding account, if one studies the mechanisms of injuries, that is, head injuries associated with cervical injuries and thoracic injuries, particularly a fractured sternum in association with mid-thoracic injuries. They may be missed because, in the first instance, they are not suspected or, although they are suspected and X-rays are taken, the fractures are not revealed either through inadequate technical quality of the pictures, poor interpretation or because the region itself, for example, the sternum and fractured ribs, may not show up fractures particularly well. Some head injuries may be overlooked because the X-rays do not reveal a fracture but another point of confusion is that a head injury can be mimicked in patients with severe chest injuries, by carbon dioxide retention and anoxia.

Mr. S., aged 55, a dock labourer, fell 30 feet on his head into the hold of a ship on 2.2.67. He sustained a fracture dislocation of $\mathrm{C}_{4} 5$ with a complete paralysis below the $\mathrm{C}_{4}$ dermatome. He was admitted initially to another hospital. X-ray of his chest revealed no fracture of his ribs or a haemothorax. Skull traction was set up and he was admitted the same day to the Liverpool Regional Paraplegic Centre. Repeat X-ray of his chest confirmed that there was no abnormality, in particular no fracture of his ribs was seen. His condition remained satisfactory for 24 hours but the following evening, that is 48 hours after injury, he suddenly became cyanosed and stopped breathing. His pulse was 48 and the blood pressure $70 / 30$. He received external cardiac massage and was given oxygen and his condition improved. He then had a fit with rapid clenching and unclenching of his teeth. Some six hours later he had a further episode of cyanosis his blood pressure dropped from I30/80 to 70/30 and he had further fits and died. At post-mortem he had a fractured sternum which was not visible on the X-ray and a considerable amount of pericardial bleeding (fig. 5). It is quite obvious that in addition to the high level of his injury, such an embarrassment to his heart caused by these fractures must have contributed to his death.

Mechanism of Death. There were eight fatalities among the 50 cases (Table IV). The causes of death can be divided into three groups. One patient with multiple injuries died of a pulmonary embolus. This is a recognised cause of death among the paraplegic patients and following any major trauma. Two patients who were chronic bronchitics and had suffered from recurrent episodes of bronchopneumonia prior to sustaining their tetraplegia, succumbed from a 


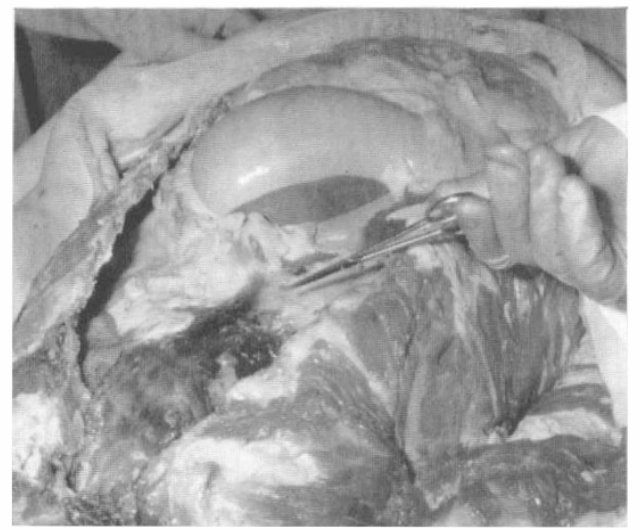

FIG. 5

Post-mortem on Mr S. showing the extensive pericardial bleeding.

TABLE IV

Analysis of the Cause of Death in the Eight Fatalities

\begin{tabular}{|c|c|c|c|c|}
\hline Level & $\begin{array}{c}\text { Age } \\
\text { (years) }\end{array}$ & $\begin{array}{l}\text { Date of Death } \\
\text { after Injury } \\
\text { (days) }\end{array}$ & Associated Injuries & Cause of Death \\
\hline $\mathrm{C}_{4}$ & 57 & 7 & Head injury & Respiratory failure \\
\hline $\mathrm{C} 4$ & 53 & 3 & Nil & Respiratory failure \\
\hline $\mathrm{C} 4$ & 40 & 2 & $\begin{array}{l}\text { Head injury } \\
\text { Tibia and fibula }\end{array}$ & Respiratory failure \\
\hline & 66 & I7 & Head injury & Respiratory failure \\
\hline $\mathrm{C} 4$ inc. & 68 & IOI & Nil (bronchitis) & Bronchopneumonia \\
\hline $\mathrm{C}_{5}$ inc. & 60 & 272 & $\begin{array}{l}\text { Head injury } \\
\text { Ribs (bronchitis) }\end{array}$ & Bronchopneumonia \\
\hline $\mathrm{C} 6$ & 52 & 8 & $\begin{array}{l}\text { Head injury } \\
\text { Femur }\end{array}$ & Respiratory failure \\
\hline $\mathrm{T}_{12}$ & 62 & I9 & $\begin{array}{l}\text { Head injury } \\
\text { Heart failure } \\
\text { Ribs and sternum }\end{array}$ & $\begin{array}{l}\text { Pulmonary em- } \\
\text { bolus }\end{array}$ \\
\hline
\end{tabular}

further episode of bronchopneumonia, while in Hospital. At post-mortem, their larger bronchi were filled with purulent secretions, the paralysis of their expiratory muscles being critical. The largest group, five cervical cases, all died within seven days of injury. They presented a remarkably uniform picture. They were all high cervical injuries, four of the five being at the $\mathrm{C}_{4} 5$ segment, only one being at the C6 segment. They were usually apprehensive and breathless, sometimes cyanosed prior to death and they died choking and coughing. Frequently they lost consciousness and had an epileptic fit following a change in 
position. There was no evidence on clinical examination that the lesion had ascended. At post-mortem there was remarkably little to find. The lungs were uniformly red and oedematous. The major bronchi were patent. Histologically

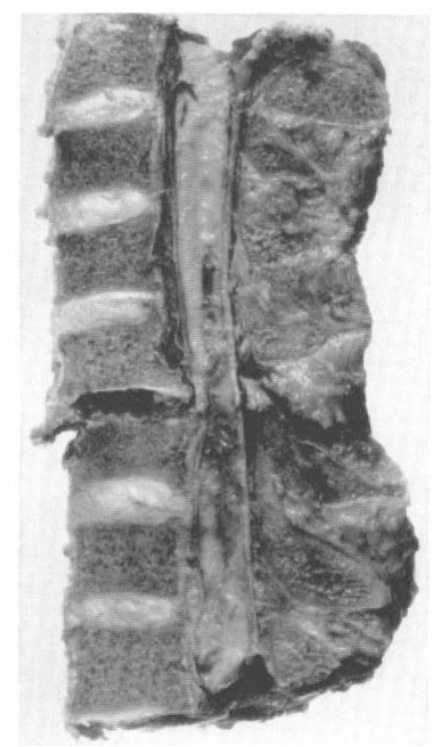

FIG. 6

Longitudinal section of the spinal cord on a tetraplegic who died eight days after injury of respiratory failure. The damage to the cord extends well above and below the fracture site.

there was little inflammatory reaction. Longitudinal section of the spinal cord was very interesting, since it showed (fig. 6) that the damage extended well above the actual level of the fracture.

The mechanism of death would seem to be that the patient survived for a few days on a small ventilatory capacity. That this proved insufficient to sustain life not because the lesion ascended but because the patients' lungs became oedematous.

\section{DISCUSSION}

Patients with paralysed intercostal and abdominal muscles from any cause whether it be injury or disease of the spinal cord or of the peripheral nerves and muscles are liable to develop aspiration pneumonia, since they are unable to effectively clear the secretions from their bronchi. It is a frequent cause of death in patients with multiple sclerosis (Reinhold, I950; Zimmerman \& Netsky, 1950).

Gravity is the main reason for the development of pneumonia in the dependant segments of the lung. Secretions tend to drip down the back of the throat and gravitate to these segments. Ramsey and Scadding (1939) showed that in I7 out of $\mathrm{I} 8$ ambulant patients with abnormal chest $\mathrm{X}$-rays secondary to upper 
respiratory tract infection, had pneumonia in these segments. A second effect of gravity is that owing to the different hydrostatic pressures in the upper and lower parts of the lung oedema fluid, too, tends to collect at the lung bases. Patients with traumatic injuries of the spinal cord are at greater risk than those with neurological disorders because, in addition to the paralysis of the intercostal and abdominal muscles, they are liable to have head or chest injuries. In this

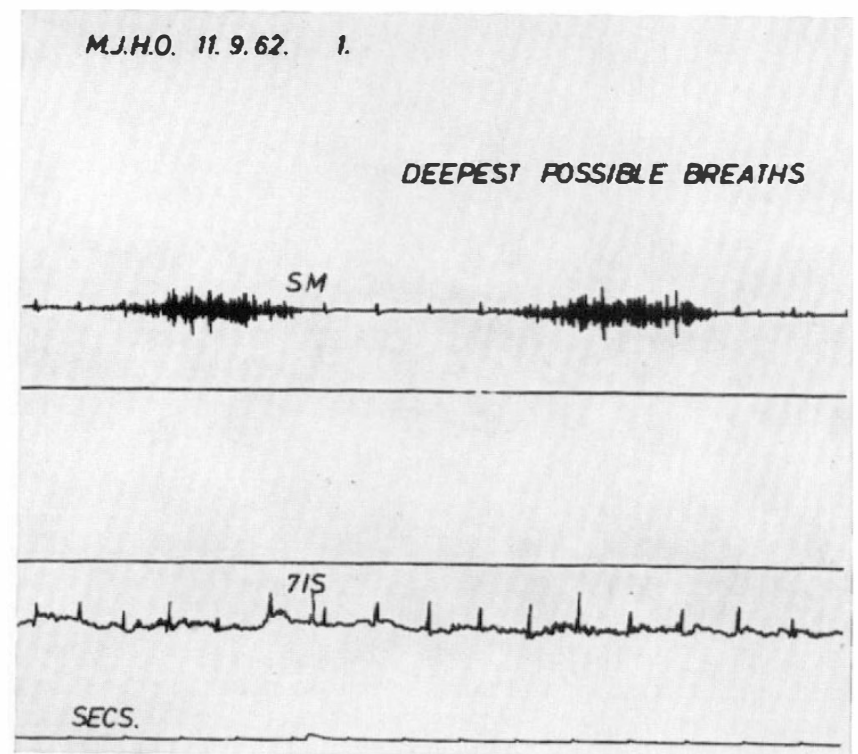

FIG. 7

Electromyographic recording from a tetraplegic patient's sternomastoid S.M. muscle and seventh intercostal space using surface electrodes in the stage of spinal shock. This shows almost complete absence of activity in the paralysed intercostal space in contrast to the well-marked activity in the sternomastoid muscle. (Guttmann and Silver, I965. F. Paraplegia, 3, I).

series, I6 patients had head injuries, I2 of these were cervical patients in 7 of whom this was serious as judged by the length of retrograde amnesia. A head injury or an episode of prolonged unconsciousness alone can produce pneumonia, due to the depression of respiration leading to patchy areas of collapse and the loss of the cough and gag reflexes. This was shown by Swank and Smedal (I948) who found pulmonary complications in 65 per cent. of young soldiers following stuporous states, produced by narcosis. Eighteen of the 29 patients with cervical injuries had pneumonia in contrast with five out of 15 patients with thoracic injuries. But a further five patients with thoracic injuries had a haemothorax and this would almost certainly be associated with underlying collapse of the lung. So that the total incidence of lung damage among the patients with thoracic spinal injuries was Io out of 15.

This damage, whatever the cause, whether it be a haemothorax, pneumonia 
or multiple areas of collapse has several deleterious effects upon the mechanics of breathing. It increases the work of breathing so that the patient has to expend a greater amount of energy to ventilate his lungs and it alters the ventilation perfusion ratio of the lung. This means that the air being drawn into the patient's lungs is not coming into contact with alveoli through which gas exchanges may take place, some of them being collapsed and oedematous. It has been shown by Silver (1963), using the method of Campbell et al. (1957) and independently by Bergofsky (1964), using a total body plethysmograph that the work of breathing in tetraplegic patients is already higher than normal. It is well recognised that in the initial stages following a high cervical cord injury, the vital capacity is grossly reduced. Cheshire (1964) studied 20 acute tetraplegic patients and found initial vital capacities ranging between $\cdot 35$ and I.6 litres. Guttmann and Silver I965) found the vital capacity in six acute tetraplegic patients, immediately after injury, to be under 2 litres In some of these patients where the diaphragm was involved it was as small as $\cdot 3$ of a litre. They attributed this low vital capacity immediately after an injury to the cervical cord, to the absence of tone in the intercostal and abdominal muscles, these muscles participating in the state of spinal shock (fig. 7). As time passed, there was a progressive increase in the vital capacity that was accompanied by a concomitant return of reflex activity in the intercostal muscles. This increase in the vital capacity was attributed largely to the more efficient action of the diaphragm and the hypertrophy of the auxillary respiratory muscles, but it was thought that the co-ordinated reflex function of the intercostal muscles could play a part in this process (fig. 8). The experimental work of Eccles et al. (1962) and Sears (1963 and 1964) on the intracellular recording from the respiratory motor neurones of the spinal cord in cats lends support to this view since they have shown that segmental reflexes which presumably are evoked by stretch afferents, play an important part in the activity of the respiratory muscles and that closer attention should be paid to the respiratory motor neurone as the final level of integration rather than to the respiratory centre in the mechanics of respiration.

It is obvious from the foregoing that the combination of a high cervical injury with a head injury and a haemothorax is a lethal injury since the factors are additive in depressing respiration. It is of interest that although the patients with thoracic injuries had a higher incidence of damage to their lungs, Io out of I5 compared with the cervical injuries, no patients in this group died, thus showing that the main factor affecting the mortality was the reduction in the vital capacity and that the occurrence of a haemothorax although obviously of great importance in reducing the total pulmonary function, was not so important as the level of the lesion and the involvement of the diaphragm.

The occurrence in one of the patients, A. S., of a delayed onset of myocardial damage, some seven days after the initial injury which progressed until some 30 days after injury is of great interest since although the damage to the heart may have taken place at the time of injury, it is possible that another mechanism was involved, since a similar picture has been reported by Segal and Tabatznik (1960), following penetrating wounds of the chest in two Bantu natives. Goodkind et al. (1960) described a similar picture following blunt trauma to the chest in college students following football games. In their cases, there was also a delayed onset of pleuro-pericardial pain, pyrexia, pleural effusion and the development of cardiac tamponade. They felt that while this could have been due to direct 
damage to the heart at the time of injury, it was more likely to be due to the post-commissurotomy syndrome, a view supported by Friedberg (I966), that it is a delayed hypersensitivity reaction of the body to blood in the pericardium or damaged myocardial tissue. Support for this view is furnished by the occurrence of persistent fever and effusion seen in some patients following haemothorax,

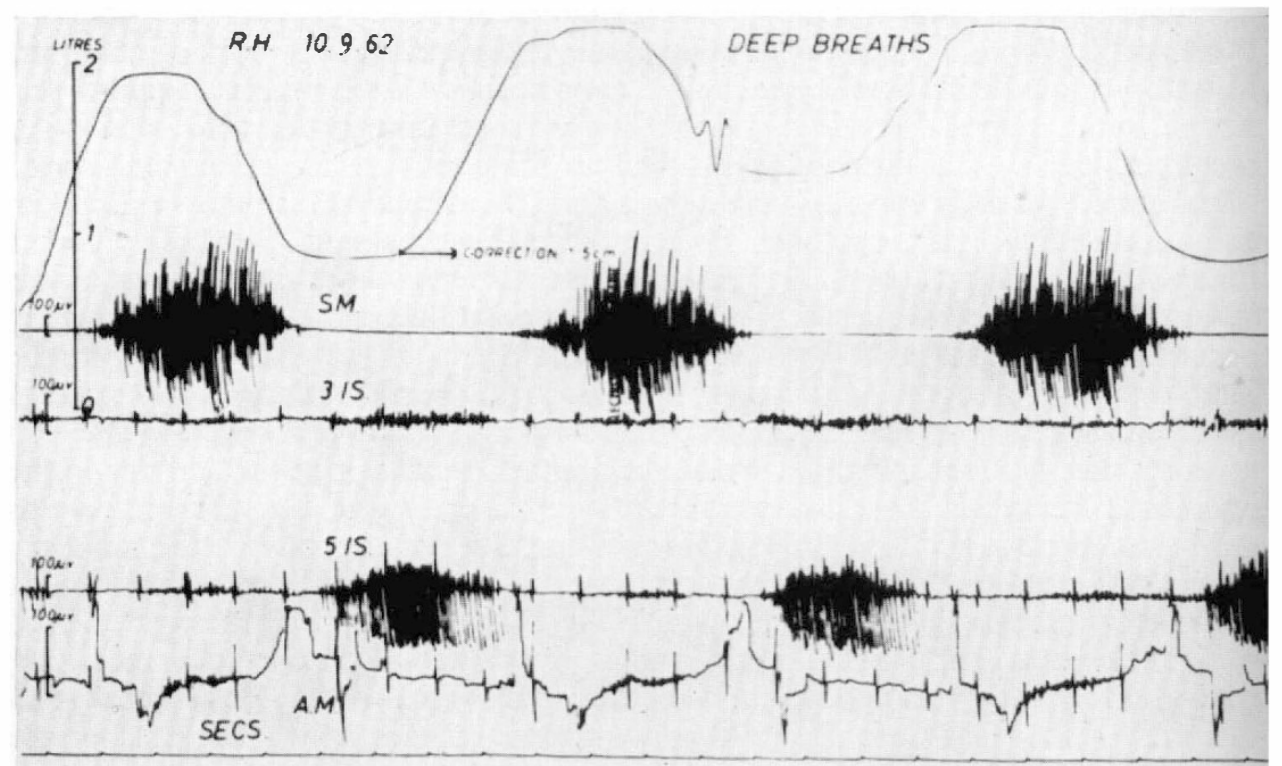

Fig. 8

Electromyographic recording from patient R. H. Io months after complete lesion below C6. Activity is present during inspiration over the third and fifth interspace and over the abdominal muscles but there is a much more marked separate expiratory rhythm in the intercostal spaces (Guttmann and Silver, I965, f. Paraplegia, 3, I).

associated with traumatic injuries of the spinal cord and the development of a picture resembling glandular fever with enlarged glands, enlarged spleen, pyrexia and atypical mononuclear cells in the blood but with a negative Paul Bunnell, also following traumatic injuries of the chest. This is identical with the postperfusion syndrome, first described by Kreel et al. (I960) and reviewed by Smith (I964). This follows cardiac operations and is thought to be due to the transfusion of infective agents at the time of operation.

The post-mortem finding of oedematous lungs with little or no inflammatory reaction in the five patients with high cervical injuries, is identical with that described by Wolman (1965) in 23 patients who died within I I days of a cervical injury at the Sheffield Unit. He reviewed the extensive literature on the production of oedema in disorders of the nervous system pointing out that cardiovascular, neurogenic, humoral influences on the pulmonary capillary permeability, airway resistance and interruption of the sympathetic pathways from the hypothalamus could play a part. Two other factors must be considered. Firstly, it has been shown that there is intense fluid retention in the early stages 
following spinal injury, especially in the cervical cases (Doggart et al., I966). Such fluid will collect in the lungs causing pulmonary oedema. Secondly, patients with high cervical injuries have a very small vital capacity that is sufficient to ventilate the patients' lungs in the early stages but when secretions collect within the lungs this proves insufficient to maintain effective oxygenation of the blood and elimination of carbon dioxide. This results in an effective increase in the patients' dead space so that eventually the patient is ventilating entirely with his dead space. When his tidal air equals his dead space then respiration becomes impossible, carbon dioxide retention will mount catastrophically and anoxia will ensue. The effect of anoxia will result in intense vaso-constriction by direct action upon the lungs with terminal respiratory failure leading to oedema. Support for this view may be gained from the work of Cheshire (I966) and Bergofsky (I964) who found persistent hypoventilation in tetraplegic patients in the later stages following spinal injury.

The implications in treatment follow directly from this. Since the high cervical patients die from respiratory failure, efforts must be made to improve the pulmonary function. Cameron et al. (1958) showed that the vital capacity of tetraplegic patients can be increased by tilting their feet up since this allows the diaphragm to assume a higher position in the chest. This also facilitates the drainage of secretions from the lungs. However, it prevents effective traction to the patients' neck so they devised boots which they fastened to the foot of the bed under the patients' feet. Although these boots are not used at Stoke Mandeville or Southport, the treatment of the patient's chest always takes precedence over that of the fractured spine, since although the patients can die of respiratory failure, providing care is exercised it is unlikely that further damage will be done to the spinal cord during turning or nursing or elevating the foot of the bed. Fluid intake should be restricted in order to prevent the development of pulmonary oedema. Furthermore, since there are such a large number of patients with pneumonia on admission or who develop pneumonia in the early stages, all patients commence antibiotics for their chest, inhalations to liquify the secretions and postural breathing exercises. Despite this regime, the loss of five patients with cervical cord injuries from respiratory failure is to be deplored since the lesion does not suddenly ascend and kill the patient but the lesion remains static and the complications ensue within the lung and if the patient can be tied over this acute stage, the vital capacity will increase. Every effort should be made by modern respiratory techniques, such as regular biochemical assessment of the blood gases, $\mathrm{pH}$ and bicarbonate, the use of positive pressure respirators and the close association with a Thoracic Centre to deal with such complications as a flail chest or a pneumothorax.

There are many unsolved problems of a physiological nature. It is not clear what the significance is of the activity detected electromyographically in the intercostal and abdominal muscles in the later stages following a cervical cord injury. It may well be that this activity is produced by the stretching of these muscles during inspiration by the contraction of the diaphragm. However, this cannot explain the activity detected during expiration. The work of Sears (1963, 1967) suggests that spinal segmental reflexes are of great importance. This problem is being further elucidated by studying the movements and the pressures generated by the chest and correlating it with the electromyographic activity. There has been much speculation but little experimental work on the production 
of pulmonary oedema in the early stages following spinal injury. Direct measurement of the blood gases and correlating them with the occurrence of oedema would further elucidate as to whether the oedema is produced by paralysis of the nervous pathways to the lung or as a secondary effect of anoxia.

\section{SUMMARY}

The chest complications found in 50 acute tetraplegic and paraplegic patients admitted during a two-year period have been described.

Eighteen of the patients were found to have an aspiration pneumonia in the early stages after injury. In I 6 of the patients it was found in the posterior basal segment of the lung.

Six patients had a haemothorax. In five of these patients it was associated with a mid-thoracic fracture of the spine.

Eight patients died, five of these were high cervical injuries. At post-mortem the lungs were oedematous.

The influence of head injury, the degree of muscular paralysis, smoking, paralytic ileus and fractures of the ribs upon the mechanics of breathing are discussed.

This study was carried out with the aid of a grant from the National Fund for Research into Poliomyelitis and Other Crippling Diseases, to whom the author is greatly indebted.

I would like to express my thanks to Dr. K. D. F. Morle, M.D., D.M.R.D., for his stimulating advice and interest throughout the last two years. I would also like to thank Miss M. A. Butler-Wright and the radiographers at the Promenade Hospital, Southport, for the uniformly high standard of their work.

\section{REFERENCES}

Bergofsky, E. H. (1964). Ann. intern. Med. 61, 435.

Cameron, G. S., Scott, J. W., Jousse, A. T. \& Botterell, E. H. (1955). Ann. Surg. I $4 \mathrm{I}, 45 \mathrm{I}$.

Campbell, E. J. M., Westlake, E. K. \& Cherniak, R. M. (I957). F. appl. Physiol. I I, 303.

Cheshire, D. J. E. (I964). Paraplegia, I, 252.

Cheshire, D. J. E. \& Foster, K. M. (I964). Paraplegia, 2, I4I.

Cheshire, D. J. E. \& CoAts, D. A. (I966). Paraplegia, 4, I.

Doggart, J. R., Guttmann, L. \& Silver, J. R. (I966). Paraplegia, 3, 229.

ECCles, R. M., SEARS, T. A. \& ShEAly, C. N. (I962). Nature, I93, 844.

Friedberg, C. K. (1966). Diseases of the Heart. Philadelphia and London: Saunders.

Goodkind, M. J., Bloomer, W. E. \& Goodyear, A. U. N. (I960). New Engl. F. Med. 263, 874.

Gregg (1967). Scientific Meeting of Soc. of Paraplegia.

Grossiord, A. Jaeger-Denavid \& Miranda, Anamaria, C. (1963). Sem. Hop. Paris, p. 663.

GuttmanN, L. \& Silver, J. R. (1965). Paraplegia, 3, I.

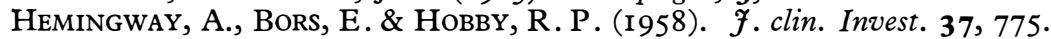

Kreel, I., ZARofF, L. I., CANTER, J. W., KRASNA, I. \& BARONOfSky, I. D. (I960). Surgery Gynec. Obstet. I III, 3 I 7.

Maglio, A., Venerando, A., Dal Monte, A. \& Lamberti-Bocconi, F. (i966). Paraplegia, 4, II6.

Ramsey, H. \& Scadding, J. G. (I939). Q. $f l$ Med. 8, 79. 
REINHOLD, M. (1950). Br. med. F. I, I60.

SEARS, T. A. (1963). Nature, I97, IOI3.

SeArs, T. A. (1964). F. Physiol. 1 75, 386.

SeArs, T. A. (1964). F. Physiol. 1 75, 404.

Segal, F. \& TABATZnik, B. (I960). Am. Heart f. 59, I75.

Silver, J. R. (1963). Paraplegia, I, 204.

SMITH, D. R. (I964). Br. med. F. I, 945.

SwANK, R. L. \& SMEDAL, M. I. (I948). Am. F. Med. 5, 219.

Talbot, H. S., Rocco, A. G. \& Conroy, M. E. (1957). In Proc. of 6th Clin. Paraplegia Conf. p. 20. Washington: Am. Vet. Admin.

Wingo, G. F. (1957). Proc. of the 6th Clin. Paraplegia Conf. p. 23. Washington: Am. Vet. Admin.

Wolman, L. (1965). Paraplegia, 2, 213.

Zimmerman, H. M. \& Netsky, M. G. (1950). Proc. Ass. Res. nerv. ment. Dis. 28, 217.

\section{DISCUSSION}

Dollfus, $P$. (France). In discussing Dr. Frankel's paper, the situation on the Continent, at least in some places, is not the same as at Stoke Mandeville. We have a lot of drugs but not enough physiotherapists, and the question I am going to ask is if any member of this Assembly has any experiences of the Bird Respirator which might be, I think, very useful, especially in certain cases of thoracic and especially cervical injuries. Sometimes we have in the very acute phase, that is some hours after the injury, a very low vital capacity and we know that tracheostomy can be dangerous for several reasons. Anaesthetists are now using post-operatively more and more the Bird Respirator which is a triggered respiratory help, and I wonder if anybody could give us his opinion about this subject.

Lipschitz, R. (S. Africa). As far as the Bird Respirator is concerned, we have six Bird Respirators in our Unit at the moment. They are of paramount importance but one must remember that the tubes leading to and from the patient are prone to infection. Therefore, when a tracheostomy is carried out, any procedure whether it be sucking the patient out or washing him out with saline must be carried out with the same meticulous care that we use in passing the catheter. This is the crux of the situation. We do it under what we call 'Recovery Room Special Care Attention'. We don't use it by mouth we use it by a plastic tracheostomy tube and the cuff must be let down regularly. But it is a magnificent instrument if used correctly, easy to control and triggered by the patient and very comfortable. Occasionally, we find that with the chest in a stove-in injury the Bird is not powerful enough, it can only give a positive pressure up to about 20-25 though officially it can do more, and then you might have to change to an Engström which also gives you a certain negative pressure.

One of our big problems has also been fluid replacement, and I agree that if you use these charts you will find that you have to give a patient more blood than almost he weighs himself. We have got over that, I don't know how well, by using central venous pressure monitory and adjusting it on that. At the same time with the high replacement of blood we have got ourselves into awful trouble unless we do the $\mathrm{pH}$ of the blood and the $\mathrm{PCO} 2$ and adjust the bicarbonate accordingly. There are certain papers coming out on that. The third thing that we have used, and we believe to be of benefit though we are not sure yet, are massive doses of cortisone, by that I mean 2,000 units two-hourly, until the patient is out of shock. This is in the literature already and we think this might be a good thing, but I was delighted to hear that people are doing away with charts because we found that our patients are coming over-transfused.

Dollfus, $P$. (France). What about the Bird without a tracheostomy, with a mask to avoid the tracheostomy? 